\title{
The interaction of tributyllead with lysosomes from rat liver
}

\author{
Marcantonio Bragadin ${ }^{\mathrm{a}, *}$, Daniele Marton ${ }^{\mathrm{b}}$, Sabrina Manente ${ }^{\mathrm{a}}$, Antonio Toninello

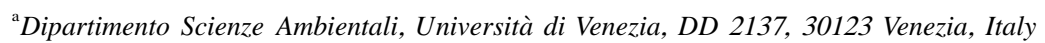 \\ ${ }^{\mathrm{b}}$ Dipartimento di Chimica Inorganica, Metallurgia ed Analitica, Università di Padova, via Marzolo 1, 35131 Padova, Italy \\ ${ }^{\mathrm{c}}$ Dipartimento di Chimica Biologica, Università di Padova, e Centro Studio delle Biomembrane, C.N.R. Padova. Viale G. Colombo 3 , 35121 Padova, \\ Italy
}

Received 15 May 2000; received in revised form 15 September 2000; accepted 18 September 2000

\begin{abstract}
The interactions of tributyllead with lysosomes from rat liver have been studied. It results that the organometal compound induces a fast alkalinization in energized lysosomes. The interpretation is that the compound is a potent proton carrier. This function could explain the toxicity, in particular at neurological level of the compound. (C) 2001 Elsevier Science B.V. All rights reserved.
\end{abstract}

Keywords: Lysosomes; Tributyllead; Uncoupling

\section{Introduction}

In the last few years the study of the interactions of trialkyl metals with the biological structures have received more and more attention since these compounds are involved in many problems of environmental concerns [1-11]. Therefore, the behaviour and the toxic effects of trialkylmetal compounds have been largely investigated in animals, to study toxicological effects, and in cells and subcellular structures in order to explain the molecular mechanisms responsible for the effects observed in the whole organism.

The molecular interactions of $\mathrm{R}_{3} \mathrm{PbCl}$ with mitochondria have been largely studied [1-3] and a model has been proposed which suggests that these compounds act as $\mathrm{Cl}^{-} / \mathrm{OH}^{-}$exchanger: leadtrialkyls enter the mitochondrial membrane as $\mathrm{R}_{3} \mathrm{PbCl}$ and are extruded as $\mathrm{R}_{3} \mathrm{PbOH}$, thus giving rise to a cyclic mechanism which explains some aspects of the toxicity of these compounds.

Recently, a new model has been proposed to explain the interactions of $\mathrm{R}_{3} \mathrm{PbCl}$ with mitochondria [6]. The authors propose that the system $\mathrm{R}_{3} \mathrm{~Pb}^{+} / \mathrm{R}_{3} \mathrm{PbOH}$ is an uncoupler (protons carrier) of oxidative phosphorylation: $\mathrm{R}_{3} \mathrm{PbCl}$ enter mitochondria as aquo-cations $\mathrm{R}_{3} \mathrm{~Pb}^{+}$and are extruded as $\mathrm{R}_{3} \mathrm{PbOH}$. The consequent cyclic mechanism gives rise to a transport of protons through the membrane

\footnotetext{
*Corresponding author. Tel.: +39-41-257-8511; fax: +39-41-2578584.

E-mail address: bragadin@unive.it (M. Bragadin).
}

with a consequent collapse of the electrochemical potential.

In order to confirm this mechanism, in this paper we have studied the interactions of $\mathrm{Bu}_{3} \mathrm{PbCl}$ with lysosomes. Like mitochondria, lysosomes are sensitive to the presence of uncouplers, but, differently from mitochondria, they do not produce ATP, but utilise ATP to pump protons in the inner compartment. As a consequence, in lysosomes the internal $\mathrm{pH}$ is acid and the potential is low and positiveinside (in mitochondria the $\mathrm{pH}$ is alkaline-inside and the potential is high and negative-inside). Furthermore, lysosomes are less complex systems than mitochondria since the respiratory chain which interferes with trialkyllead compounds and proteic channels pore [12] are absent.

Therefore, lysosomes are a good test to confirm the already proposed uncoupling mechanism.

We have chosen the tributyllead derivative since it is the most toxic for animals and the most destructive for cells $[4,11]$.

\section{Materials and methods}

Lysosomes from rat liver have been prepared following the procedure indicated by Savant et al. [13]. The protein concentration has been determined by the Lowry method [14]. The lysosomes, after the last centrifugation of the preparation, have been resuspended in a medium containing: $0.1 \mathrm{M}$ sucrose, $50 \mathrm{mM} \mathrm{K} \mathrm{SO}_{4}, 20 \mathrm{mM}$ Hepes $\mathrm{pH}$ 7.4, $2.5 \mathrm{mM} \mathrm{MgSO}_{4}$ and $500 \mu \mathrm{M}$ EGTA and stored at 
$0^{\circ} \mathrm{C}$. The protein concentration of the resuspended lysosomes was $20 \mathrm{mg} / \mathrm{ml}$. The dye acridine orange (AO) 1.0 $\mathrm{mM}$ in ethanol was used.

Acridine orange uptake by lysosomes was followed spectrophotometrically at $20^{\circ} \mathrm{C}$ by a Jenway 6400 Spectrophotometer at $492 \mathrm{~nm}$. After addition to the medium $(2.5 \mathrm{ml})$ operating of $20 \mu \mathrm{l}$ of lysosomes and $20 \mu \mathrm{l}$ dye AO (1 $\mathrm{mM})$ before the addition of $2 \mathrm{mM}$ ATP, the instrument was calibrated at zero absorbance.

The rates of $\mathrm{H}^{+}$efflux from energised lysosomes after addition of $\mathrm{NH}_{3}$, bafilomycin, duramycin, FCCP or $\mathrm{Bu}_{3} \mathrm{~Pb}-\mathrm{Cl}$ were calculated assuming an internal volume of lysosomes of $4 \mu \mathrm{l} / \mathrm{mg}$ lysosomal protein [15] and from the slope of the plot. Absorbance changes against time when the compound is added

All reagents were of analytical grade. $p$-Trifluoromethoxycarbonyl cyanide phenylhydrazone (FCCP), Acridine Orange and $\mathrm{Bu}_{3} \mathrm{PbCl}$ were supplied by FLUKA

\section{Results and discussion}

In lysosomes, the ATP-dependent proton pump (vacuolar-type $\mathrm{H}^{+}$ATPase) pumps the protons into the matrix. Since the membrane is not permeable to protons, their influx gives rise to acidification and, as consequence, to a positive potential in the internal matrix. The positive-inside potential opposes to a marked acidification since the protons are positively charged. In the presence of $\mathrm{Cl}^{-}$ions in the suspending medium, the presence of a positiveinside potential induces the uptake of $\mathrm{Cl}^{-}$ions through a selective channel [16]. As a consequence of the uptake of these negative ions, the internal potential collapses and the $\mathrm{pH}$ decreases from 5.2 [17] to about 4.5 [16,17]. The acidification in lysosomes is easily followed by the dye (AO) [18]. This dye is a weak base and following the behaviour of permeant weak bases [16], it crosses the membrane as electroneutral compound and is accumulated (and more concentrated) in the internal matrix due to the more acid $\mathrm{pH}$ inside the membrane. This accumulation gives rise to a quenching of the absorption spectrum. Therefore, as Fig. 1a shows, the internal acidification can be followed by absorbance quenching at a fixed wavelength (492 nm) [18]. About $20 \mathrm{~min}$ after ATP energization, a steady state is reached in which the internal $\mathrm{pH}$ is about 4,5 and the internal potential is very low (about +20 $\mathrm{mV}$ ) [15] when the medium contains $0.125 \mathrm{M} \mathrm{Cl}^{-}$. In these conditions the addition of $\mathrm{Bu}_{3} \mathrm{PbCl}$ causes a fast increase in absorbance of $\mathrm{AO}$, thus indicating internal alkalinization (Fig. 1a) which in energized lysosomes can be due to many effects.

(i) Weak permeant bases such as ammonia, are rapidly accumulated in the internal acid matrix [16] and the accumulation enhances the internal $\mathrm{pH}$ (Fig. 1b), trace 1; the calculated rate of $\mathrm{H}^{+}$efflux is $60 \mathrm{p}$ moles $\mathrm{H}^{+} / \mathrm{mg}$ protein/min). This effect, however, is induced only by

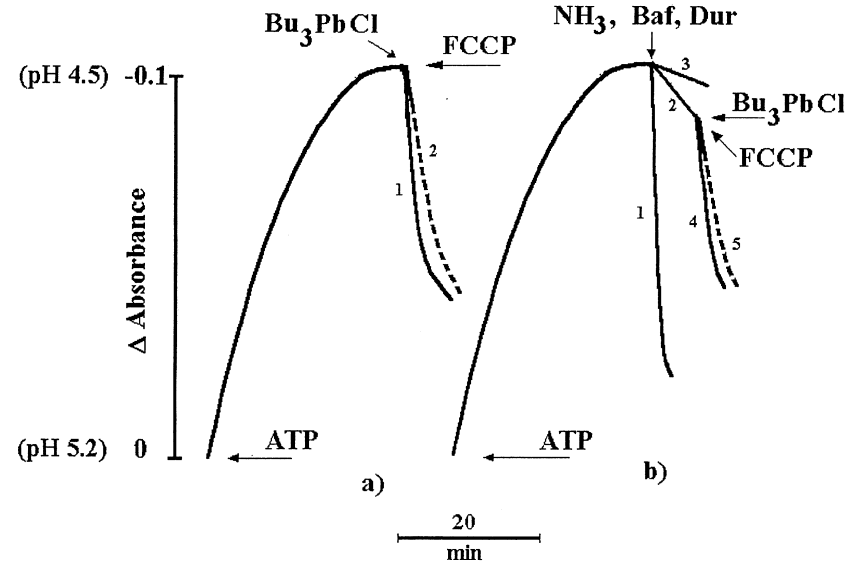

Fig. 1. Acidification of lysosomes in a $\mathrm{KCl}$ medium and alkalinization induced by $\mathrm{Bu}_{3} \mathrm{PbCl}(0.8 \mu \mathrm{M})$, FCCP $(0.5 \mu \mathrm{M}), \mathrm{NH}_{3}(10 \mathrm{mM})$, bafilomycin $(50 \mathrm{nM})$, duramycin $(10 \mu \mathrm{g} / 100 \mu \mathrm{g}$ protein). The arrows indicate the points of addition of the compounds. Lysosomes are acidified by addition of $2 \mathrm{mM}$ ATP in the incubating medium $(2.5 \mathrm{ml})$. Medium composition: $0.125 \mathrm{M} \mathrm{KCl}, 20 \mathrm{mM}$ Hepes $\mathrm{pH} 7.4,2.5 \mathrm{mM} \mathrm{MgCl}{ }_{2}, 500$ $\mu \mathrm{M}$ EGTA and $8 \mu \mathrm{M}$ AO. Lysosomes $0.2 \mathrm{mg} / \mathrm{ml}$. Before ATP addition the instrument was calibrated at zero absorbance at a fixed wavelength (492 nm). (a) The alkalinization induced by addition of $0.8 \mu \mathrm{M} \mathrm{Bu} \mathrm{Bu}_{3} \mathrm{PbCl}$ (trace 1 , full line) or $0.5 \mu \mathrm{M}$ FCCP (trace 2 , dotted line) is shown. (b) The alkalinization induced by addition of $10 \mathrm{mM} \mathrm{NH}_{3}$ as $\left(\mathrm{NH}_{4}\right)_{2} \mathrm{SO}_{4}$ (trace 1), $50 \mathrm{nM}$ bafilomycin (Baf) (trace 2), $10 \mu \mathrm{g} / 100 \mu \mathrm{g}$ protein duramycin (Dur)(trace 3 ) is shown. The addition of duramycin gives rise to a small absorbtion which has been subtracted from the figure. Traces 4 and 5 refer to the alkalinization induced by organolead $(0.8 \mu \mathrm{M})$ and FCCP $(0.5 \mu \mathrm{M})$, respectively.

massive doses of weak permeant base [15,18-20], above millimolar concentration. This is not the case of $\mathrm{Bu}_{3} \mathrm{PbCl}$, the effect of which occurs below micromolar concentration.

(ii) Internal alkalinization arises from inhibition of the proton pump. As Fig. 1b (trace 2) shows, the addition of bafilomycin, a potent inhibitor of the vacuolar ATPase [21] causes a proton efflux, but this efflux rate is very slow $(2 \mathrm{p}$ moles $\mathrm{H}^{+} / \mathrm{mg}$ protein $/ \mathrm{min}$ ) if compared to that obtained by addition of $\mathrm{Bu}_{3} \mathrm{PbCl}\left(16.8 \mathrm{p}\right.$ moles $\mathrm{H}^{+} / \mathrm{mg}$ protein/ min, trace 4). Therefore, even if $\mathrm{Bu}_{3} \mathrm{PbCl}$ would inhibit the vacuolar ATPase, the very fast observed alkalinization cannot be due to this inhibitory effect.

(iii) Alkalinization of internal $\mathrm{pH}$ may arise from inhibition of the chloride channel. As Fig. 1b (trace 3) shows, the addition of duramycin, a potent inhibitor of the chloride channel [22] does not induce an appreciable fast release of protons from the internal matrix $\left(\mathrm{H}^{+}\right.$efflux rate: $0.8 \mathrm{p}$ moles $\mathrm{H}^{+} / \mathrm{mg}$ protein/min). Therefore, the fast alkalinization induced by $\mathrm{Bu}_{3} \mathrm{PbCl}$ cannot be due to an inhibition of the chloride channel of lysosomes.

(iv) Uncouplers are proton carriers and, as Fig. 1a shows (trace 2), the addition of FCCP, a potent proton carrier, causes a fast proton release $\left(\mathrm{H}^{+}\right.$efflux rate: $15.2 \mathrm{p}$ moles $\mathrm{H}^{+} / \mathrm{mg}$ protein/min) from the lysosomal matrix.

Since the same effect is induced by $\mathrm{Bu}_{3} \mathrm{PbCl}\left(\mathrm{H}^{+}\right.$efflux rate: $23.2 \mathrm{p}$ moles $\mathrm{H}^{+} / \mathrm{mg}$ protein/min, Fig. 1a, trace 1), 
this behaviour suggests the possibility that $\mathrm{Bu}_{3} \mathrm{PbCl}$, like FCCP acts as a potent proton carrier. The same behaviour has been already proposed to explain the interaction of trialkyllead chlorides with mitochondria [6].

In mitochondria, however, another mechanism has been proposed to explain the interactions of $\mathrm{R}_{3} \mathrm{MCl}(\mathrm{M}=$ metal, $\mathrm{R}=$ alkyl) with the membrane and in particular the toxicity of trialkyllead compounds [1-3]. This mechanism proposes that trialkylmetals enter mitochondria as $\mathrm{R}_{3} \mathrm{MCl}$ electroneutral compounds and are extruded as $\mathrm{R}_{3} \mathrm{MOH}$ compounds, thus giving rise to a cycling mechanism in which the starting compound acts as $\mathrm{Cl}^{-} / \mathrm{OH}^{-}$exchanger. This mechanism can be applied to lysosomes to explain the experimental behaviour of Fig. 1: in this case the compound should enter as $\mathrm{Bu}_{3} \mathrm{PbOH}$ since the $\mathrm{pH}$ is more acid inside, but, being $\mathrm{Cl}^{-}$also accumulated inside, the $\mathrm{Bu}_{3} \mathrm{PbCl}$ compound is extruded.

In order to distinguish between the two mechanisms, we have carried out the experiments of Fig. 2 in a medium containing the potassium carrier valinomycin [18], and in the absence of chloride ions. Since lysosomes contain in the matrix about $0.1 \mathrm{M}$ potassium, the presence of valinomycin allows the extrusion of potassium ions from the internal matrix to the external medium. As one can see (Fig. 2), the addition of ATP induces acidification of the matrix. When valinomycin (Val) is added, the acidification rises and the behaviour is the same as that due to the $\mathrm{Cl}^{-}$ uptake showed in Fig. 1: the positive-inside potential induced by ATP addition collapses by $\mathrm{K}^{+}$extrusion and not by $\mathrm{Cl}^{-}$uptake, thus allowing the $\mathrm{pH}$ to rise to a more acid value. $\mathrm{Bu}_{3} \mathrm{PbCl}$ and $\mathrm{FCCP}$ behave in the same manner, both in the presence (Fig. 2b) (the $\mathrm{H}^{+}$efflux rates

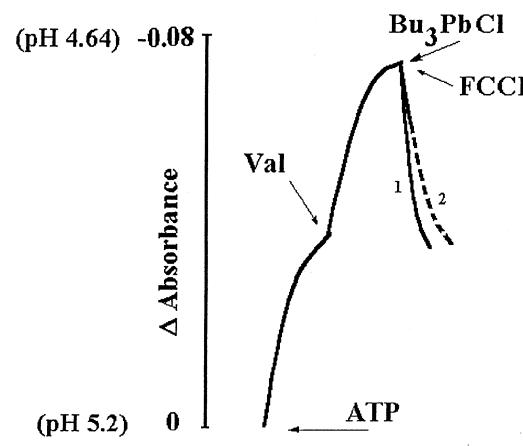

a)

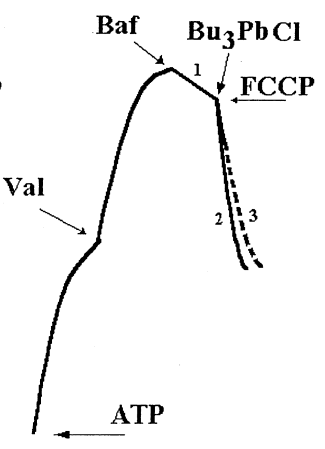

b)

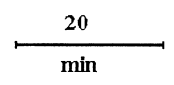

Fig. 2. Acidification of lysosomes in $\mathrm{a} \mathrm{Cl}^{-}$free medium and alkalinization induced by $8 \mu \mathrm{M} \mathrm{Bu} 3 \mathrm{PbCl}, 0.1 \mu \mathrm{M}$ FCCP and $50 \mathrm{nM}$ bafilomycin after Valinomycin ( Val) $(18 \mu \mathrm{M})$ addition. The arrows indicate the points of addition of the compounds. Lysosomes are acidified by ATP 2 mM added in the incubating medium. Medium composition: $100 \mathrm{mM}$ sucrose, $50 \mathrm{mM} \mathrm{K}_{2} \mathrm{SO}_{4}, 20 \mathrm{mM}$ Hepes $\mathrm{pH} 7.4,2.5 \mathrm{mM} \mathrm{MgSO}_{4}, 500 \mu \mathrm{M}$ EGTA, $8 \mu \mathrm{M}$ AO. (a) The alkalinization induced by addition of $8 \mu \mathrm{M} \mathrm{Bu} \mathrm{BbCl}_{3}$ (trace 1) or $0.1 \mu \mathrm{M}$ FCCP (trace 2) is shown. (b) The alkalinization induced by addition of $50 \mathrm{nM}$ Bafilomycin (Baf) (trace 1), and of $8 \mu \mathrm{M}$ $\mathrm{Bu}_{3} \mathrm{PbCl}$ (trace 2) and of $0.1 \mu \mathrm{M} \mathrm{FCCP} \mathrm{(trace} \mathrm{3)} \mathrm{is} \mathrm{shown.}$ induced by Bafilomycin (trace 1 ), $\mathrm{Bu}_{3} \mathrm{~Pb}-\mathrm{Cl}$ (trace 2 ) and FCCP (trace 3) are $0.8,12$ and $10 \mathrm{p}$ moles $\mathrm{H}^{+} / \mathrm{mg}$ protein/min respectively) and in the absence of bafilomycin (Fig. 2a); the $\mathrm{H}^{+}$efflux rates for $\mathrm{Bu}_{3} \mathrm{~Pb}-\mathrm{Cl}$ (trace 1) and FCCP (trace 2) are 10.8 and $9.2 \mathrm{p}$ moles $\mathrm{H}^{+} / \mathrm{mg}$ protein/min respectively), a potent inhibitor of the vacuolar pump. In this case, the mechanism of $\mathrm{Cl}^{-} / \mathrm{OH}^{-}$ exchange cannot be proposed since $\mathrm{Cl}^{-}$is absent from the medium.

The results therefore support the hypothesis that $\mathrm{Bu}_{3} \mathrm{PbCl}$ behaves as uncoupler, by enhancing the proton permeability in the biological membrane. This mechanism (which however does not exclude the other possibility) implies that $\mathrm{Bu}_{3} \mathrm{PbCl}$ enters the lysosomal membrane as electroneutral compound $\mathrm{Bu}_{3} \mathrm{PbOH}$. In order to justify this hypothesis, the following solvolytic and hydrolytic equilibria of $\mathrm{Bu}_{3} \mathrm{PbCl}$ species in aqueous solution must be considered [23,24]:

$$
\begin{array}{ll}
\mathrm{Bu}_{3} \mathrm{PbCl}_{(\mathrm{aq})} & \leftrightarrows \mathrm{Bu}_{3} \mathrm{~Pb}_{(\mathrm{aq})}^{+}+\mathrm{Cl}^{-} \\
\mathrm{Bu}_{3} \mathrm{~Pb}_{(\mathrm{aq})}^{+}+2 \mathrm{H}_{2} \mathrm{O} \leftrightarrows \mathrm{Bu}_{3} \mathrm{PbOH}_{(\mathrm{aq})}+\mathrm{H}_{3} \mathrm{O}^{+}
\end{array}
$$

$\mathrm{Bu}_{3} \mathrm{~Pb}^{+}$behaves as a weak acid $\left(\mathrm{p} K_{\mathrm{a}}=9.1\right.$ [24]) and at $\mathrm{pH}$ 7.4 the ratio $\left[\mathrm{Bu}_{3} \mathrm{~Pb}^{+}\right] /\left[\mathrm{Bu}_{3} \mathrm{PbOH}\right]$ is about 50 . Therefore, even if in a very small amount, the hydroxide is always present and its uptake is favoured by the acid conditions inside the membrane. Once inside, $\mathrm{Bu}_{3} \mathrm{~Pb}^{+}$species is formed and is extruded as lipophilic cation. The balance of the whole cyclic mechanism is the transport of a proton through the membrane as in the case of the uncoupling mechanism. The extrusion is caused by the proton pump which induces the positive-inside potential with consequent extrusion of the lipophilic cation $\mathrm{Bu}_{3} \mathrm{~Pb}^{+}$. It has already been demonstrated that the cation $\mathrm{Bu}_{3} \mathrm{~Pb}^{+}$is carried through the membrane by a potential-driven mechanism [6]. The same behaviour has been observed with respect to the interaction of trialkyltin compounds with mitochondria [11] and lysosomes [25,] since also these compounds are weak acids and lipophilic.

It cannot be excluded, however, that $\mathrm{Bu}_{3} \mathrm{PbCl}$, like other organometal compounds, inhibit the vacuolar ATPase [26] (this study is not the aim of this paper). But, if this is the case, the effects observed after addition of $\mathrm{Bu}_{3} \mathrm{PbCl}$ or bafilomycin (the inhibitor of ATPase) to the matrix should be similar. The experiments of Fig. $2 b$, show clearly that this is not true: the alkalinization induced by the organolead is faster than that caused by the bafilomycin.

In order to exclude the possibility of a competitive ATPase inhibitory effect between Bafilomycin and $\mathrm{Bu}_{3} \mathrm{~Pb}-$ $\mathrm{Cl}$, we have operated in the presence of varying amounts of Bafilomycin. The results (not shown) indicate that even if a dose of $500 \mathrm{nM}$ (instead of $50 \mathrm{nM}$ ) of Bafilomycin is employed, the alkalinization rate induced by Bafilomycin alone and by $500 \mathrm{nM}$ Bafilomycin plus $\mathrm{Bu}_{3} \mathrm{~Pb}-\mathrm{Cl}(0.8 \mu \mathrm{M}$ in Fig. 1, trace 4, or $8 \mu \mathrm{M}$ in Fig. 2, trace 2) is identical. This behaviour demonstrate that $50 \mathrm{nM}$ Bafilomycin 
inhibits completely the ATPase and that the (slow) alkalinization which occurs when the ATPase is inhibited, is only due to a proton leak from the inner matrix.

Therefore, an uncoupling mechanism may better explain the effect of $\mathrm{Bu}_{3} \mathrm{PbCl}$. The consequent extrusion of $\mathrm{Bu}_{3} \mathrm{~Pb}^{+}$must be ascribed to the positive-inside potential created either by the $\mathrm{K}^{+}$influx when the pump is inhibited (Fig. 2b) or by the proton influx when the pump is operating (Fig. 2a). The same uncoupling mechanism may be also invoked to explain the results of the interaction of $\mathrm{Bu}_{3} \mathrm{PbCl}$ with lysosomes in a medium containing $\mathrm{Cl}^{-}$ions (see, Fig. 1): in this case the extrusion of $\mathrm{Bu}_{3} \mathrm{~Pb}^{+}$is regulated by the extrusion or by the influx of $\mathrm{Cl}^{-}$, in other words, when the pump is inhibited (not shown) or not inhibited (Fig. 1a).

This mechanism, even if it does not exclude the previously proposed mechanism of a $\mathrm{Cl}^{-} / \mathrm{OH}^{-}$exchange for mitochondria, could explain some toxic effects of $\mathrm{Bu}_{3} \mathrm{PbCl}$ compounds and in particular the neurotoxicity.

In fact, the uncoupling mechanism implies that in any case an uncoupler crosses the membrane as charged ion (in this case as $\mathrm{Bu}_{3} \mathrm{~Pb}^{+}$) by a potential-driven mechanism. Since in nerve cells the membrane potential has the highest value and is negative-inside, this fact could explain why nerve cells are the preferential target of trialkyllead compounds [27].

\section{References}

[1] W.N. Aldridge, B.W. Street, D. Skilleter, Biochem. J. 168 (1977) 353.

[2] D.N. Skilleter, Biochem. J. 146 (1975) 465.

[3] W.N. Aldridge, J.E. Cremer, C.J. Threlfall, Biochem. Pharmacol. 11 (1962) 835.
[4] T. Nielsen, K.A. Jensen, Nature 274 (1978) 602.

[5] K. Hayakawa, Jpn. J. Hyg. 26 (1971) 377.

[6] M. Bragadin, D. Marton, M. Murgia, V. Rizzoli, G. Scutari, R. Deana, J. Inorg. Biochem. 69 (1998) 259.

[7] J. Gabrielska, J. Sarapuk, S. Przestalski, Z. Naturforsch C 52 (1997) 209.

[8] H. Kleszcynsca, J. Hladyszowski, H. Pruchnik, S. Przestalski, Z. Naturforsch C 52 (1997) 65.

[9] A.A. Seawright, A.W. Brown, W.N. Aldridge, R.D. Verschole, B.W. Street, Dev. Toxicol. Environ. Sci. 8 (1980) 71.

[10] E.R. Ramstoek, W.G. Hoelska, H.E. Ganther, Toxicol. Appl. Pharmacol. 54 (1980) 251.

[11] M. Bragadin, D. Marton, J. Inorg. Biochem. 68 (1997) 75.

[12] L. Scorrano, V. Petronilli, P. Bernardi, J. Biol. Chem. 272 (1997) 12295.

[13] P.L. Savant, S. Shibko, U.S. Kumta, A.L. Tappel, Biochim. Biophys. Acta 85 (1964) 82.

[14] O.H. Lowry, N.J. Rosenbrough, D.L. Farr, R.J. Randall, J. Biol. Chem. 193 (1951) 265.

[15] S. Ohkuma, Y. Moriyama, T. Takano, J. Biochem. 94 (1983) 1935.

[16] J. Mellman, R. Fuchs, A. Helenius, Ann. Rev. Biochem. 55 (1986) 663.

[17] Y. Murijama, M. Maeda, M. Futai, FEBS Lett. 302 (1992) 18.

[18] P. Dell' Antone, Biochem. Biophys. Res. Commun. 86 (1979) 180.

[19] P. Dell'Antone, M. Bragadin, P. Zatta, Biochim. Biophys. Acta 1270 (1995) 137

[20] P.O. Seglen, Methods Enzymol. 96 (1983) 737.

[21] E.J. Bowman, A. Siebers, K. Altendorf, Proc. Natl. Acad. Sci. USA 85 (1988) 7922.

[22] D.K. Stone, X.S. Xie, E. Racker, J. Biol. Chem. 258 (1984) 2701.

[23] F.E. Brinckman, J.M. Bellama, in: F.E. Brinckmann, J.M. Bellama (Eds.), Organometals and Organometalloids. Occurrence and Fate in the Environment, 17th ACS Symposium series meeting of the American Chemical Society, Anaheim, CA, 1978.

[24] U. Belluco, M. Giustiniani, M. Graziani, J. Am. Chem. Soc. 89 (1967) 6494.

[25] M. Bragadin, D. Marton, G. Scutari, P. Dell'Antone, J. Inorg. Biochem. 78 (2000) 205.

[26] E.J. Bowman, J. Biol. Chem. 258 (1983) 15238.

[27] R.M. Booze, C.F. Mactutus, Experientia 46 (1990) 292. 